\title{
Variability in the Syntax of Idioms
}

\begin{abstract}
Given that the meaning of idioms is not predictable from the literal meaning of their parts, we can broadly define idioms as expressions with a non-compositional interpretation. Since language is a compositional system, this characteristic of idioms might suggest that they are atomic building blocks of language with no internal syntax. However, that turns out not to be the case. This paper explores the syntax of English verbal idioms and their degree of compositionality. Idioms do have an internal syntactic structure that is actually variable to an extent and, despite being superficially similar, different idioms exhibit different syntactic properties. The topics discussed include the variability of determiners in idioms, the subcategorisation of idioms based on their relative compositionality into two groups that behave differently with respect to their syntactic flexibility, and the identification of grammatical categories that are obligatory components of certain idioms but not others.
\end{abstract}

Keywords: idioms; syntax; compositionality; determiners; passivisation

\section{Variabilnost skladnje idiomov}

\section{POVZETEK}

Glede na to, da pomena idiomov ni moč predvideti na podlagi dobesednega pomena njihovih sestavnikov, lahko idiome $\mathrm{v}$ grobem definiramo kot izraze z nekompozicionalno interpretacijo. Ker je jezik kompozicionalen sistem, bi lahko na podlagi te lastnosti idiomov sklepali, da so idiomi atomarni gradniki jezika brez notranje skladnje, vendar se izkaže, da ni tako. Prispevek obravnava skladnjo angleških glagolskih idiomov in njihovo stopnjo kompozicionalnosti. Idiomi imajo notranjo skladnjo, ki je do neke mere variabilna, in čeprav so si na prvi pogled enake, imajo podskupine idiomov različne skladenjske značilnosti. Obravnavane teme vključujejo variabilnost členov in ostalih določilnikov v idiomih, klasifikacijo idiomov glede na njihovo skladenjsko prožnost in prepoznavanje slovničnih kategorij, ki so obvezen sestavni del določenih idiomov.

Ključne besede: idiom; skladnja; kompozicionalnost; določilniki; pasivizacija 


\section{Variability in the Syntax of Idioms}

\section{Preliminaries}

Faced with the task of illustrating what an idiom is, a proficient language user will readily suggest a number of typical examples, such as:

(1) a. to bite the dust

b. to have a bone to pick (with somebody)

The idioms in (1) belong to arguably the most frequent idiom type, namely verbal idioms, and the paper will focus on examples of this kind as well. Their defining feature is that they contain a lexical verb, and will thus commonly consist of a combination of a verb and a nominal phrase functioning as its object (for a further discussion of verbal idioms, see Harwood et al. (2016) and references therein). The key property shared by all idioms is the unpredictability of their meaning, which cannot be derived from the literal meaning of the constituent parts. Let us, at least for the time being, settle on the following definition that captures this core understanding of what an idiom is:

(2) An idiom is an expression with a non-compositional interpretation.

We discuss this definition and its theoretical corollaries in sections 2 and 3 before proceeding to the core subject matter of the paper, namely the syntactic properties of English verbal idioms (with a few passing references to Dutch data). Even though idioms are often considered frozen, atomic units of language, we will see that they have an internal syntactic structure that is actually variable to an extent, and that, despite being superficially similar, different verbal idioms exhibit different syntactic properties. In section 4 we discuss the variability of determiners in idioms, section 5 deals with subcategories of idioms that behave differently with respect to their syntactic flexibility, while section 6 is concerned with grammatical categories that are obligatory components of certain idioms but not others. Section 7 concludes the paper.

\section{The Principle of Compositionality}

To put the definition in (2) into perspective and explain the importance of the key term 'non-compositional', we first take a step back and look at the bigger picture with a basic, deceptively simple question: What is language? Most often, we think of language as a means a method of human communication that makes use of one of several available channels, be it spoken, written, or signed. This use of language, however, is made possible because the faculty of language at its core is a system of mapping form to meaning (and of course vice versa).

A crucial property of the human language system is discrete infinity. Language is made of a finite set of individual, discrete building blocks (a finite set of meaningless phonemes make up a set of smallest meaning-bearing units, morphemes) that combine to build an infinite number of sentences that can, in principle, also be infinitely long. ${ }^{1}$ This property is one of the design features of language - as described by the linguistic anthropologist Charles F. Hockett

Due to the recursive nature of syntactic rules, a sentence of any length can be embedded under a further superordinate clause, e.g. 'She said (that) ...' for declaratives or 'He wonders ...' for interrogatives. This results in an even longer, fully grammatical (although admittedly impractically long) sentence. 
in the sixties - that distinguishes human language from animal communication (Hockett 1966; Hauser, Chomsky, and Fitch 2002).

Given this discrete infinity property of language, the form-meaning mapping needs to be systematic and predictable in such a way that makes it compatible with the observation that speakers are able to reliably produce and understand completely novel phrases and sentences. How is the meaning of these larger linguistic units computed, then? This is where the principle of compositionality comes into play. Its modern formulation is generally attributed to the German philosopher, logician, and mathematician Gottlob Frege, ${ }^{2}$ and the version of the principle commonly used in linguistics is as follows (cf. Partee 1984, Pelletier 2004, Dever 2006, among others):

(3) The meaning of a complex expression is determined by the meaning of its constituent parts and the manner in which they are combined.

By means of illustration, let us examine the meaning of the following sentence.

(4) I saw a man with binoculars.

We can see that the sentence is ambiguous, as there are two possible meanings associated with it. Either (a) 'I used binoculars to observe a man', or (b) 'I saw a man who happened to be in possession of binoculars'. Where do the two interpretations come from? First, note that none of the individual words has a double meaning and that they of course appear in the same linear order (as there is only one sentence). Crucially, language is organised hierarchically, not linearly, and there are two different syntactic structures associated with the sentence, each giving rise to one of the two interpretations. In the first structure, 'with binoculars' modifies the verb, resulting in meaning (a), and in the second one, 'with binoculars' modifies the object, resulting in meaning (b). While the constituent parts of the sentence in (4) remain the same, the possible ways they combine into a larger syntactic structure determine the possible interpretations of the sentence, in accordance with the second part of the principle of compositionality.

\section{Idioms and Compositionality}

In light of what has been discussed so far, we can see that idioms are special in that they apparently flout the principle of compositionality. Consider the meaning of the following sentence, with the idiom indicated in italics:

(5) Ned Stark bit the dust.

The interpretation of (5) is that Ned Stark died. However, none of the lexical items the idiom comprises corresponds in any way to the idiomatic meaning:

- bite $=$ use one's teeth to cut into something

- the $=$ definiteness

- dust = fine, dry powder consisting of tiny particles of earth or waste matter 
The meaning of such an idiom is thus not built compositionally. ${ }^{3}$ A possible way to reconcile idioms with compositionality is to view them as having no internal structure at all - they are stored in our mental lexicon as single, opaque, atomic items (cf. among others Gibbs and Gonzales 1985; McGlone, Glucksberg, and Cacciari 1994; see also Jackendoff 1997 and works in the phraseological tradition, e.g. Cowie 1981, 1998; Mel'cuk 1988; Howarth 1996). If any of the items that make up the idiom in (5) are replaced, even by synonyms, the figurative interpretation is lost, as illustrated in (6). This follows if idioms are viewed as multi-word expressions that function as single words in syntax.

(6) a. \# bite the dirt ${ }^{4}$

b. \# bite some dust

c. \# chew the dust

However, there are also good indications that idioms are to some extent built compositionally. In general, idioms are formed in a manner which obeys the regular syntactic rules of the language (cf. among others Fellbaum 1993; Nunberg, Wasow, and Sag 1994; Ifill 2002; McGinnis 2002; Svenonius 2005; Everaert 2010; Stone 2013). Let us examine some arguments in support of this stance.

Firstly, bite the dust formally behaves like any other fully regular verbal phrase (VP). This conformity to regular phrase structure rules is shown below, where the form of the idiomatic VP repeated in (7a) is parallel to that of the non-idiomatic VPs in (7b) and (7c).

(7) a. Ned Stark bit the dust.

b. Ned Stark bit the bread.

c. Ned Stark swept the dust.

Secondly, idioms exhibit regular word order, and we make a comparison between English and Dutch to illustrate this point. Both main and embedded clauses in English have the SubjectVerb-Object order, while Dutch is SVO with the verb-second rule in effect in main clauses, and $\mathrm{SOV}$ in embedded clauses. Importantly, in both cases, the idioms in the two languages conform to the regular word order. English idiomatic examples are given in (8), and Dutch ones in (9):

(8) Main clause:

a. Yesterday Ned Stark bit the dust.

[SVO]

Embedded clause:

b. I think that Ned Stark bit the dust.

[SVO]

(9) Main clause:

a. Gisteren gaf mijn camera de geest.
yesterday gave my camera the spirit
'Yesterday my camera broke down.'

$[\mathrm{SVO}, \mathrm{V} 2]$

\footnotetext{
Nunberg, Sag, and Wasow (1994, 495-99) keep apart the notions of compositionality, the level of which is determined by the possibility of analysing the meaning of an idiom in terms of the contribution to meaning of the individual parts of the idiom (as will be discussed later in this paper), and transparency, which they define as the ease of recovering the etymology of the idiom - or constructing the motivation for its use - once we know its meaning. Howarth $(1996,18)$ uses the term motivation for the latter.

4 The \# sign is used throughout to indicate the unavailability of idiomatic interpretation.
} 


\section{Embedded clause:}

$\begin{array}{lllllll}\text { b. Ik denk dat mijn camera de } & \text { geest gaf. } & \text { [SOV] } \\ \text { I think that my camera the } & \text { spirit } & \text { gave } & \\ \text { 'I think that my camera broke down.' } & & & \end{array}$

It is therefore meaningful to consider the syntax of idioms as an object of study. Idioms are not atomic, despite their relative rigidity, and they do have an internal structure. At the same time, as the reader will have observed by now, idioms also interact with the rest of the sentence they are a part of and conform to it morphosyntactically (the form of the verbal part of the idiom changes accordingly without affecting the availability of the idiomatic interpretation). We will examine these and other properties of idiom syntax in the present paper.

\section{Determiner Variability}

The literature on idioms has traditionally and predominantly focused on their lexical content (i.e. the verb and the noun and the relation between them in the case of typical verbal idioms), much more than on grammatical/functional categories, but if we are to study idiom syntax then it is precisely the grammatical content of idioms we should turn our attention to. A clear place to start is thus to look at determiners in idioms and their properties.

A key paper in that regard is Fellbaum (1993), which examines the form of determiners in English idioms and the degree to which it is actually invariable. As it turns out, determiners in idioms may, subject to systematic constraints, change without any loss of idiomaticity. This is therefore an additional argument in favour of idioms having meaningful internal structure.

Fellbaum $(1993,275)$ observes that certain nominal phrases (NPs) occurring in idioms are actually denoting, i.e. they have a referent. In this respect the nominal part of the idiom resembles a conventional metaphor. We can identify what such NPs denote - for example, in the context of the idioms in (10), 'the hatchet' refers to a dispute, whereas 'a bone' refers to a contentious issue.

(10) a. to bury the hatchet

b. to have a bone to pick (with somebody)

An additional argument in support of Fellbaum's observations about the referential nature of object NPs in idioms is that we are able to refer back to just that part of the idiom with a pronoun in the subsequent discourse. For the idioms in (10) we illustrate this in (11), with the coreferential pronoun marked in italics:

(11) a. George and Harry seemed ready to bury the hatchet there and then, but as it turned out they only buried it months later.

b. I have a bone to pick with you and $i t$ is a big one.

\subsection{Indefinite Article}

Importantly, in these cases the use of determiners is predictable, and the range of possible determiner variation and modification of the NP depends on general language rules that apply outside idioms as well. The use of the article in (10b), for example, is thus compatible with the interpretation of the NP - there is a specific indefinite contentious issue to be discussed. In 
accordance with this, the idiom may be modified as in (12a); likewise, the article may be replaced by quantifiers, including negative ones, as in (12b).

(12) a. to have a certain/particular bone to pick

b. to have many/few/no bones to pick

Just to reiterate, these possibilities are all also in accordance with the rules of literal language:

(13) a. to ask a question

b. to ask a certain/particular question

c. to ask many/few/no questions

When the idiom contains a verb of creation (i.e. a verb whose object denotes an entity that does not exist prior to the action expressed by the verb), the modification by certain/particular is predictably impossible (14a), just as in literal language (14b).

(14) a. *She made a certain scene.

b. *She wove a certain rug.

\subsection{Zero Article}

Idioms with zero articles also occur, such as the often discussed one in (15a), where 'strings' denote connections. Accordingly, the idiomatic NP is a plural indefinite, and grammatically behaves as such, allowing a range of modifications shown in (15b).

a. to pull strings

b. to pull many/no/these/certain strings

In contrast, zero articles in idioms also pattern with singular nouns, which is unexpected from a syntactic point of view:

(16) a. to save/lose face

b. not to be able to make head or tail (of something)

c. to take heart

However, an explanation may be found if we, once more, consider the denotation of the nominal part of these idioms. In each case, they denote (i.e. are metaphors for) mass nouns - honour, sense, and courage, respectively - and mass nouns are expected to appear without an article (Fellbaum 1993 , 292). Such idioms are also predictably compatible with quantifiers, when the referent is quantifiable, as in (17), for example:

(17) They couldn't make much head or tail of his story.

\subsection{Definite Article}

Different possible uses of the definite article can likewise be found in idioms. The non-specific or institutional use (such NPs are also known as weak definites, cf. Aguilar-Guevara and Zwarts (2013), among others) is illustrated in (18) for literal language. The sentence is still true, even if Sue and Mary went to two different post offices (which means that the use of the definite article cannot be due to the ostensible uniqueness of the post office in the context). 
(18) Sue went to the post office today, and so did Mary.

According to Fellbaum $(1993,281)$, the same institutional use of the definite article can be seen in the idiom in (19), where 'the clock' refers to (social) progress. This particular reading is lost as soon as the definite article is substituted for another, both in literal language (20a) and in idioms (20b):

(19) This court ruling will set the clock back.

(20) a. Sue and Mary went to a post office today.

b. This court ruling will set (all) clocks back.

Alternatively, the appearance of the definite article in (19) may also be linked to the existence of a pragmatically presupposed non-specific referent, which can be referred to without having occurred previously in the discourse, i.e. another regular use of the definite article.

Using a definite article is also the only option when the NPs referent is inferable from preceding discourse, again in both literal and idiomatic examples. Compare the following two cases from Fellbaum $(1993,283)$ :

(21) When John gives a lecture, he always forgets the notes.

(22) At every party John manages to break the ice.

In the idiomatic example (22), the nominal part of the idiom, i.e. 'the ice', refers to social unease in the context set up by the presence of 'at every party'. Note how this idiomatic reading disappears (or is at least pragmatically infelicitous) in the absence of a suitable context in (23).

(23) \# At every supermarket John manages to break the ice.

Next, the definite article is used in NPs with a given referent, known to the participants in the discourse, again in both literal and idiomatic language. In (24a), 'the beans' refers to a secret whose existence and content are known to the participants.

(24) a. John spilled the beans about his girlfriend.

b. Bob and John buried the hatchet.

The idiom NP can be modified by a quantifier that is compatible with that interpretation, as in (25a), or have the article replaced by a demonstrative, as in (25b).

(25) a. John spilled all the beans about his girlfriend.

b. Bob and John finally buried that hatchet.

So far, we have seen a variety of cases where the NP part of the idiom is (a) referential, and (b) the choice of determiner and its possible variation conforms to the regular rules for the use of articles and other determiner elements in the language. These facts reinforce the idea that idioms have regular syntax and are more compositional than initially believed. However, there is also a group of idioms with a definite article which does not fall under any of the categories described above. Some examples of such idioms are as follows: 
(26) a. kick the bucket

b. bite the dust

c. shoot the breeze

d. chew the fat

e. give the slip (to somebody)

What these have in common is that their NP object is non-referential - therefore, in contrast to the examples discussed previously, we cannot decompose these idioms. They are assigned a meaning as a whole (the first two mean to die, the next two to chat (casually/extensively), and the last one to evade or escape), while there is no meaning associated with just the nominal part. In other words, the object NP cannot be seen as a metaphor for a subpart of the idiom's meaning.

These cases thus illustrate a particular idiomatic use of the definite article, which cannot be replaced by another form. In (27), for example, any change to the article results in the loss of idiomatic meaning:

(27) a. George gave the slip to his pursuers.

b. \# George gave althat slip to his pursuers.

The use of the definite article in idioms such as those in (26) is decidedly not context-dependent either, as shown by the examples in (28) - compare these to the to break the ice examples (22) and (23).

(28) a. In the hospital, John kicked the bucket.

b. At the party, John kicked the bucket.

c. At the supermarket, John kicked the bucket.

We look more closely at further differences between these two groups of idioms in the following section.

\section{Syntactic Flexibility}

To recap, we have identified two types of verbal idioms, based on their semantic - more specifically, referential - properties. Idioms of the first type are relatively more compositional, in that their constituent parts map to individual components of the meaning of the idiom as a whole. Idioms of the second type, in contrast, do not display that property, as the individual parts of the idiom have no referents of their own.

Nunberg, Sag, and Wasow (1994) explore the distinctions between the two groups of idioms further, respectively labelling them idiomatically combining expressions (ICEs, for short) and idiomatic phrases (IdPs). They recognise the previously addressed referential properties of object NPs in ICE idioms, supported by the observations that these individual parts can be quantified and serve as antecedents to anaphoric coreferential pronouns. Two examples of quantified NPs in idioms are given in (29), while examples with coreferential pronouns (from: Nunberg Sag, and Wasow 1994, 502) are provided in (30).

(29) a. to touch a couple of nerves

b. to pull yet more strings 
(30) a. We thought tabs were kept on us, but they weren't.

b. Kim's family pulled some strings on her behalf, but they weren't enough to get the job.

c. Pat tried to break the ice, but it was Chris who succeeded in breaking $i$.

Importantly, the authors also observe a systematic correlation between the degree of compositionality and the overall syntactic flexibility of idioms. First, ICEs allow for the modification of the object NP by adjectives and relative clauses; since the NP has a meaning of its own, it stands to reason that this meaning can be independently modified, as in (31).

(31) a. Pat got the job by pulling the strings that weren't available to anyone else.

b. John left no legal stone unturned.

Note how in (31b) the adjective is compatible with the idiomatic meaning of 'stone' in this idiom: John exhausted all legal recourses. Such modification, on the other hand, is not possible with the non-compositional IdPs, even when the modifiers are chosen to be semantically compatible with the idiom:

(32) a. \# Bob kicked the final bucket.

b. \# We chewed the fat that we found most interesting for about an hour.

Second, ICE idioms allow for the passivisation of the object, while IdPs do not. The idioms thus preserve their meaning in ICE examples such as the following:

(33) a. I could tell that a nerve was certainly touched by that coarse remark.

b. The beans were spilled by Bob in the end.

In contrast, the idiomatic reading is lost when passivisation is applied to an IdP, as demonstrated in (34).

(34) a. \# The fat was chewed by the three friends for the better half of an hour.

b. \# The bucket was kicked by Jack.

Third, in a similar vein, while this is allowed in the case of ICEs, the object of an IdP cannot readily be displaced for the purpose of topicalisation. Compare:

(35) a. Well, these strings he would not pull for you.

b. Those beans Bob has most certainly spilled already.

(36) a. \# The breeze they definitely shot for at least an hour.

b. \# The bucket Jack has gone and kicked.

\section{Dependency of Idioms on Functional Material}

In the preceding sections we discussed the variability in the syntax of idioms both in the area of determiner selection and the availability of syntactic operations, such as modification, passivisation, and topicalisation. The findings show that idioms follow general syntactic rules and have an internal structure. At the same time, they fall into different subcategories with regard to the degree of their compositionality. 
Beyond that, there is yet another dimension of idiom syntax variation that requires attention. As briefly mentioned at the beginning, verbal idioms are properly embedded in the larger syntactic structure, so we find them conforming to it morphosyntactically, e.g. in terms of subject-verb agreement. It is, however, not the case that all idioms are specified only for the lexical content, i.e. what verb-noun combination they consist of, while the verb can appear in any grammatical form. We also come across idioms dependent on particular functional categories that are therefore also part of the idioms in question (cf. Harwood and Temmerman 2015).

Thus we find English idioms that are dependent on the passive voice, such as those in (37). Without the passive, the idiomatic reading is suddenly not available anymore, as shown by the examples in (38), which do not mean 'I was saved from a difficult situation at the last moment' and 'I was moved to sympathy or emotion', respectively.

(37) a. to be saved by the bell

b. to be touched by an angel

(38) a. \# The bell saved me from what could have been a rather embarrassing speech.

b. \# An angel really touched me when I was watching that film.

Yet other English idioms crucially depend on the progressive aspect. We can see in (40) that as soon as the indicative or the perfect forms are used, the meaning associated with the idioms in (39) is lost.

(39) a. to be spitting feathers

b. to be flying blind

c. to be pushing at an open door

(40) a. \# The evil emperor spat feathers after he heard about the destruction of the Death Star.

b. \# Since there is no precedent for countries leaving the EU, the UK has flown blind in the wake of the Brexit vote.

c. \# My proposals to switch to a green renewable energy source were met with unanimous approval. It turns out I had been pushing at an open door the entire time.

For a further discussion on passive and progressive idioms, see also Bowers (2010), Sailor and Ahn (2010), Horvath and Siloni (2015, 2016), Harwood (2013, 2015), and Sailor (2014), among others.

There are also some examples of idioms that appear to be dependent on a particular tense:

(41) a. fell off the back of a lorry/truck (past)

b. heads will roll (future)

However, the dependence is superficial. While these idioms are most commonly used in the tense forms given above, and may therefore be listed in dictionaries with a particular tense as well, the decisive criterion is always whether the idiomatic meaning is preserved if we change the 
grammatical category. As shown in (42), the past tense in (41a) and the future tense in (41b) are not necessary ingredients of the two idioms, since the idiomatic interpretation is still present. ${ }^{5}$

(42) a. And how do we know that everything in this dump hasn't fallen off the back of a lorry?

b. Heads roll daily over at the Daily Mail HQ.

\section{By Way of Conclusion}

In this paper we have looked at three areas in which the syntax of idioms is not necessarily fixed. One and the same idiom may appear with various determiner forms as long as the regular rules of determiner use in non-idiomatic language allow for it. An exception seems to be idioms where the nominal part has no referent of its own, which makes them decidedly non-compositional - such idioms appear with a definite article by default. We label these idiomatic phrases (IdPs), while the relatively more compositional idioms whose constituents can be mapped onto individual parts of the idiomatic interpretation are called idiomatically combining expressions (ICEs). This distinction has been explored in the continuation of the paper, examining another area of syntactic variability. While ICEs may undergo adjectival and relative clause modification, passivisation, and topicalisation of the object, such syntactic operations are not possible with idioms of the IdP category. Lastly, we have looked at functional material that may constitute a necessary part of an idiom. There are English idioms that do not comprise only lexical material, i.e. a particular combination of a verb and a noun, but are dependent on the presence of grammatical categories, such as passive voice or progressive aspect.

These findings lead us to the necessary conclusion that the idioms discussed are far from being monolithic and syntactically frozen, but instead display an active internal syntactic structure and interact with the syntax of the clauses they are embedded in. The present overview highlights the particular syntactic properties and dimensions along which idioms may differ from one another. These considerations are of importance not only to theoretical linguists, but also with regard to the way idioms and their properties are - or should be - presented in (learner's) dictionaries.

Further research is needed to assess the cross-linguistic validity of the ICE-IdP distinction and the generalisations that follow from it. A contribution to that end is the work done on Dutch within the Syntax of Idioms project (Corver et al. 2017), while at the Department of English at the University of Ljubljana MA-level students have taken the initial steps in comparing the

A related issue, though more theory-specific than the topics discussed in the rest of the paper, is the link between the IdP-ICE distinction and the clausal functional hierarchy. The findings of Cinque (1999, 2001, 2016), Nauze (2008), and others working in the generative framework suggest that functional material is, just like lexical elements, hierarchically organised. For example, elements associated with tense appear higher in the syntactic structure than those associated with, say, progressive aspect. IdP idioms, which are non-compositional, need to correspond to a complete syntactic constituent, i.e. a contiguous section of the structure. We can then pose the question of how big this constituent can be (that is, how much of the functional material it can encompass), and the findings are consistent with the proposed hierarchy - if an IdP depends on a particular functional category, it will depend on all categories lower on the hierarchy as well. The syntactic size of IdP idioms, in this sense, may differ across languages. In English, idioms may depend on the progressive aspect and voice (as seen in this section; the reader can also confirm that the idioms discussed are all IdPs by applying the syntactic flexibility tests from section 5), while in Dutch some depend on the perfect aspect and root modality, categories located even higher in the hierarchy (Harwood and Temmerman 2015). 
syntactic properties of English idioms to those of idioms in Slovenian and a handful of other languages as part of a seminar course offered in the 2016/17 spring semester. Hopefully, this paper will serve as an inspiration for other such endeavours.

\section{References}

Aguilar-Guevara, Ana, and Joost Zwarts. 2013. "Weak Definites Refer to Kinds.” In Recherches linguistiques de Vincennes 42, edited by Claire Beyssade and Roberta Pires de Oliveira, 33-60. Vincennes: Presses Universitaires.

Bowers, John. 2010. Arguments as Relations. Cambridge, MA: MIT Press.

Cinque, Guglielmo. 1999. Adverbs and Functional Heads: A Crosslinguistic Perspective. Oxford: OUP.

-. 2001. "Restructuring and the Order of Aspectual and Root Modal Heads." In Current Studies in Italian Syntax: Essays Offered to Lorenzo Renzi, edited by Guglielmo Cinque and Giampaolo Salvi, 137-55. Amsterdam: Elsevier.

—. 2016. "A Source of Parametric Variation in the Lexicon." Linguistica 56 (1): 83-92. http://dx.doi. org/10.4312/linguistica.56.1.83-92.

Corver, Norbert, Jeroen van Craenenbroeck, Eefje Boef, Kristel Doreleijers, William Harwood, Marko Hladnik, Sterre Leufkens, and Tanja Temmerman. 2017. Database of Dutch Dialect Idioms (DaDDI). Accessed July 21. http://languagelink.let.uu.nl/idioms/.

Cowie, Anthony P. 1981. "The Treatment of Collocations and Idioms in Learners' Dictionaries." Applied Linguistics 2 (3): 223-35. http://dx.doi.org/10.1093/applin/II.3.223.

—, ed. 1998. Phraseology: Theory, Analysis, and Applications. Oxford: Oxford University Press.

Dever, Josh. 2006. “Compositionality.” In The Oxford Handbook of Philosophy of Language, edited by Ernest Lepore and Barry C. Smith, 633-66. Oxford: Oxford University Press.

Everaert, Martin. 2010. “The Lexical Encoding of Idioms." In Syntax, Lexical Semantics, and Event Structure, edited by Malka Rappaport Hovav, Edit Doron, and Ivy Sichel, 76-99. Oxford: Oxford University Press.

Fellbaum, Christiane. 1993. "The Determiner in English Idioms." In Idioms: Processing, Structure and Interpretation, edited by Cristina Cacciari and Patrizia Tabossi, 271-96. Hillsdale, NJ: Erlbaum.

Gibbs, Raymond W., and Gayle Gonzales. 1985. "Syntactic Frozenness in Processing and Remembering Idioms.” Cognition 20: 243-59. http://dx.doi.org/10.1016/0010-0277(85)90010-1.

Harwood, William. 2013. "Being Progressive is Just a Phase: Dividing the Functional Hierarchy." PhD diss., Universiteit Gent.

—. 2015. "Being Progressive is Just a Phase: Celebrating the Uniqueness of Progressive Aspect Under a Phasebased Analysis." Natural Language and Linguistic Theory 33 (2): 523-73. http://dx.doi.org/10.1007/ s11049-014-9267-3.

Harwood, William, Marko Hladnik, Sterre Leufkens, and Tanja Temmerman. 2016. "Idioms: Phasehood and Compositionality." Ms., Utrecht University and KU Leuven.

Harwood, William, and Tanja Temmerman. 2015. "Pushing the Boundaries: Idioms and Phases in Dutch Dialects and English." CGSW 30, University of Chicago, May 22-23.

Hauser, Marc D., Noam Chomsky, and W. Tecumseh Fitch. 2002. "The Language Faculty: What is it, Who has it, and How did it Evolve?" Science 298: 1569-79.

Hockett, Charles F. 1966. “The Problem of Universals in Language.” In Universals of Language, edited by J. Greenberg, 1-29. Cambridge, MA: MIT Press. 
Horvath, Julia, and Tal Siloni. 2015. "Idioms: The Type-sensitive Storage Model.” BCG8L: The Grammar of Idioms, KU Leuven Campus Brussels, June 4-5.

—. 2016. "Idioms: The Type-sensitive Storage Model.” Ms., Tel Aviv University.

Howarth, Peter Andrew. 1996. Phraseology in English Academic Writing: Some Implications for Language Learning and Dictionary Making. Tübingen: Max Niemeyer.

Ifill, Tim. 2002. "Seeking the Nature of Idioms: A Study in Idiomatic Structure." Ms., Haverford College.

Jackendoff, Ray. 1997. The Architecture of the Language Faculty. Cambridge, MA: MIT Press.

McGlone, Matthew, Sam Glucksberg, and Cristina Cacciari. 1994. "Semantic Productivity and Idiom Comprehension.” Discourse Processes 17 (2): 167-90. http://dx.doi.org/10.1080/01638539409544865.

McGinnis, Martha. 2002. “On the Systematic Aspect of Idioms.” Linguistic Inquiry 33 (4): 665-72. http:// dx.doi.org/10.1162/ling.2002.33.4.665.

Mel'čuk, Igor A. 1988. "Semantic Description of Lexical Units in an Explanatory Combinatorial Dictionary: Basic Principles and Heuristic Criteria." International Journal of Lexicography 1 (3): 165-88. http://dx.doi. org/10.1093/ijl/1.3.165.

Nauze, Fabrice. 2008. "Modality in Typological Perspective.” PhD diss., Universiteit van Amsterdam.

Nunberg, Geoffrey, Ivan Sag, and Thomas Wasow. 1994. "Idioms." Language 70 (3): 491-538. http://dx.doi. org/10.1353/lan.1994.0007.

Partee, Barbara H. 1984. "Compositionality." In Varieties of Formal Semantics, edited by Fred Landman and Frank Veltman, 281-312. Dordrecht: Foris.

Pelletier, Francis J. 2004. "The Principle of Semantic Compositionality." In Semantics: A Reader, edited by Steven Davis and Brendan S. Gillon, 133-56. New York: OUP.

Sailor, Craig. 2014. "The Variables of VP Ellipsis.” PhD diss., University of California LA.

Sailor, Craig, and Byron Ahn. 2010. "The Voices in our Heads: The VoiceP in English.” Morphological Voice and its Grammatical Interfaces: Theoretic Modelling and Psycholinguistic Validation, University of Vienna, June 25-27.

Stone, Megan S. 2013. "Can Idioms be Passivized?” Coyote Papers: Working Papers in Linguistics, Linguistic Theory 21, University of Arizona.

Svenonius, Peter. 2005. "Extending the Extension Condition to Discontinuous Idioms." Linguistic Variation Yearbook 5: 227-63. http://dx.doi.org/10.1075/livy.5.08sve. 